\title{
MigRACIÓN INTERNA INDÍGENA DESDE EL IsTMO VERACRUZANO: NUEVAS ARTICULACIONES REGIONALES
}

\author{
Internal indigenous migration from the Veracruz Isthmus: new regional associations \\ Emilia Velázquez-Hernández
}

Resumen: El objetivo de este trabajo es analizar las nuevas articulaciones regionales que se crean a través de las migraciones internas. Para ello, se toma como estudio de caso las migraciones que desde mediados de la década de 1990 se realizan desde el Istmo veracruzano hacia la frontera norte de México y los campos de agricultura intensiva de Sinaloa. Se muestra que, a través de la migración laboral de trabajadores nahuas y popolucas de la Sierra de Santa Marta, regiones antes inconexas se articulan actualmente de manera desigual.

Palabras clave: migración interna, trabajadores indígenas, reconfiguración regional.

Abstract: This article explores how the internal migration creates new regional links. The analyses is grounded in the case study about the migrations that took place since the 1990s between the Istmo veracruzano and the north border of Mexico in one hand, and the Istmo veracruzano through the fields of intensive agriculture of Sinaloa in other hand. This study shows that migration of nahuas and popolucas workers from Sierra de Santa Marta allows that regions before unconnected are now plenty and unequal articulated.

Keywords: internal migration, indigenous workers, regional changement.

\footnotetext{
Emilia Velázquez Hernández, doctora en Ciencias Sociales por el Colegio de Michoacán. Profesora e investigadora en el Centro de Investigaciones y Estudios Superiores en Antropología Social, unidad Golfo. Temas de especialización: análisis regional, historia política, tenencia de la tierra. Correo electrónico: emivel@ciesas. edu.mx, emivel@prodigy.net.mx.
}

Enviado a dictamen: 08 de abril de 2013 Aprobación: 27 de abril de 2013

Revisiones: 1 


\section{Introducción}

E

n marzo de 2010, el gobierno veracruzano puso en marcha un controvertido programa para apoyar el retorno de familias veracruzanas que vivían en Ciudad Juárez y otras ciudades fronterizas, las cuales habían empezado a emigrar a mediados de la década de 1990 para emplearse en las empresas maquiladoras ubicadas en la frontera norte del país. ${ }^{1}$ En noviembre de 2010 se llevó a cabo el séptimo y último vuelo aéreo en el que retornaron los migrantes veracruzanos que decidieron acogerse a dicho programa gubernamental. Estos migrantes procedían de varios municipios del centro y sur del estado de Veracruz; en esta última región sobresalían las municipalidades de Coatzacoalcos, Cosoleacaque, Minatitlán, Mecayapan y Soteapan como los principales lugares de origen de quienes retornaban desde la frontera. ${ }^{2}$

Un año después, en agosto de 2011, la Coordinadora General de la Delegación Coatzacoalcos de la Secretaría del Trabajo informaba que esta dependencia había registrado en dicho año la salida de 6000 trabajadores hacia los campos agrícolas de Sinaloa, en donde se emplearían como jornaleros agrícolas. La misma funcionaria indicaba que estos trabajadores provenían principalmente "de los municipios indígenas de la Sierra de Santa Marta, específicamente de Tatahuicapan, Mecayapan y Soteapan", y que en Sinaloa percibían "salarios aproximados a los 1400 pesos quincenales."

Ambas informaciones aluden a dos hechos inéditos en el Istmo veracruzano: a) la movilidad masiva de mano de obra hacia sitios ubicados a más de 1000 kilómetros de sus lugares de origen, ya sea para emplearse en la industria maquiladora de exportación, en el caso de Ciudad Juárez, o para ser contratados por las agroindustrias dedicadas a la producción de hortalizas de invierno destinadas al mercado norteamericano, principalmente de aquellas ubicadas en el estado de Sinaloa; y b) la conversión del Istmo veracruzano en una región expulsora de mano de obra, una tendencia diametralmente opuesta a la que durante la mayor parte del siglo XX había caracterizado al sur de Veracruz, cuando la industria petrolera y petroquímica, así como la colonización agropecuaria, atrajeron de manera constante población de diferentes puntos de la entidad veracruzana y de otros estados del país.

Estos dos acontecimientos tienen que ver con los ajustes estructurales propios de la fase actual del capitalismo, en la que predomina la relocalización de capitales y mano de obra. Ambos sucesos también derivan de decisiones personales y familiares para aprovechar nuevas oportunidades de trabajo, aun cuando éstas impliquen la movilización hacia lugares lejanos y desconocidos. De esta manera, espacios regionales antes inconexos se han convertido en espacios desigualmente articulados en torno a la demanda de mano de obra y a la movilidad laboral. Esta reconfiguración regional, propiciada por intereses ligados a la globalización económica, se ha logrado gracias a la activa participación de hombres y mujeres que han tomado la decisión de abandonar sus terruños por meses o años, pero que también optan por regresar a sus lugares de origen cuando los costos personales de vivir fuera de sus ámbitos familiares y comunitarios resultan demasiado altos. En este proceso, las personas insertas en los nuevos circuitos laborales se han visto obligadas a "extender los límites de [sus] geografías", incluyendo los de sus "geografías imaginadas" (Hernández, 2007: 70).

En este contexto, el presente artículo tiene como objetivo analizar cómo y bajo qué circunstancias la población indígena de la Sierra de Santa Marta, en el Istmo veracruzano, ha debido insertarse en circuitos laborales que desde hace casi 20 años articulan desigualmente el norte del país y el sur de Veracruz. Para ello, ubicaré los contextos regionales de los lugares de expulsión y atracción de esta mano de obra, con el objetivo de mostrar las condiciones estructurales que han favorecido esta interconexión de regiones geográficamente distantes, pero económica y socialmente articuladas. A la par, mostraré las experiencias migratorias de hombres y mujeres procedentes de localidades de los municipios de Soteapan y Mecayapan.

Para realizar este trabajo me he basado en tres tipos de fuentes: 1) la revisión de estudios relevantes 
para entender el desarrollo económico y demográfico del Istmo veracruzano, así como para conocer las condiciones que han favorecido el crecimiento económico de la industria maquiladora de exportación en la frontera norte y de la agricultura intensiva de hortalizas en el noroeste del país; 2) la consulta de fuentes hemerográficas; y 3) el trabajo de campo que he llevado a cabo en diversos poblados de los municipios de Mecayapan y Soteapan en estancias escalonadas entre 1993 y 2001, además de un nuevo trabajo de campo realizado en distintos momentos de 2008 a 2012 para entrevistar a migrantes de retorno de Ciudad Juárez y a los jornaleros estacionales que anualmente van a trabajar a Sinaloa. Con estos últimos platiqué en el perído de tres o cuatro meses que permanecen en sus pueblos antes de regresar nuevamente a Sinaloa.

Los municipios de Mecayapan y Soteapan se ubican en la Sierra de Santa Marta, una elevación montañosa localizada en la parte norte del Istmo veracruzano; en esta sierra se concentra el mayor conglomerado de población indígena del sur de Veracruz (Velázquez, 2010). Hasta 1997, la Sierra de Santa Marta estuvo política y administrativamente dividida en tres municipios: Mecayapan —nahua-, Soteapan - popoluca-y Pajapan —nahua- Sin embargo, en ese año la legislatura local aprobó la creación del municipio de Tatahuicapan, en el cual fueron incluidos tanto poblados de origen nahua como popoluca.

En estrecha relación con las diversas condiciones naturales de la sierra - tipos de suelo, altura sobre el nivel del mar-, así como con las políticas agrícolas y agrarias de los últimos 50 años, en la Sierra de Santa Marta se han diferenciado cuatro zonas productivas: cafetalera, maicera, ganadera-maicera y ganadera. Los migrantes nahuas y popolucas a los que se refiere esta investigación son originarios de las zonas maicera y cafetalera.

\section{El Istmo veracruzano: de la atracción a la expulsión de mano de obra}

El Istmo veracruzano ${ }^{4}$ es una región que comenzó a delinearse como tal a partir de mediados del siglo XIX, cuando primero Minatitlán, y más tarde Coatzacoalcos, se convirtieron en importantes centros de producción y comercio al amparo de la extracción masiva de maderas preciosas, la construcción del Ferrocarril Nacional de Tehuantepec y el establecimiento hacia finales de dicho siglo de grandes plantaciones de hule, café y caña de azúcar. Estas actividades atrajeron hacia Minatitlán y Coatzacoalcos a numerosa población proveniente de otras regiones del país y del extranjero (Velázquez, 2006: 80-90).

Durante gran parte del siglo XX hubo un flujo constante de inmigrantes hacia esta región, atraídos tanto por la demanda de trabajo en la actividad petrolera como por las posibilidades de colonizar los grandes espacios que permanecían deshabitados. En el caso de la población obrera, ésta empezó a arribar en las primeras décadas del siglo XX, estableciéndose tanto en Minatitlán (Uribe, 2009) como en los campos petroleros, en donde crearon nuevos poblados Las Choapas, Nanchital, Cuichapa, Agua Dulce(Prévôt-Schapira, 1994). Otra oleada de inmigración ocurrió en las décadas de 1950 a 1980 con el auge de la petroquímica; esta vez, los trabajadores recién llegados se asentaron principalmente en las periferias de Coatzacoalcos, Minatitlán y Cosoleacaque (Nolasco, 1979). Por lo que respecta a los inmigrantes rurales, éstos concurrieron al Istmo en diferentes periodos tanto por cuenta propia como cobijados en programas gubernamentales ${ }^{5}$ para fundar ejidos, colonias y ranchos ganaderos. ${ }^{6}$

Bajo estas circunstancias, durante casi todo el siglo XX tuvo lugar un notable crecimiento demográfico, ${ }^{7}$ el cual fue especialmente relevante en cuatro municipios: Coatzacoalcos, que pasó de 28347 habitantes en 1950 a 109588 en 1970; Minatitlán, municipio que en 1950 tenía 34993 habitantes, cifra que para 1970 había ascendido a 94 621; Cosoleacaque, que pasó de 8510 habitantes en 1950 a 20531 en 1970; y finalmente Las Choapas, donde en 1950 se registraron 9366 habitantes y para 1970 se reportaron 39466 (Nolasco, 1979: 12). ${ }^{8}$

El crecimiento demográfico de las décadas de 1950 a 1980 fue apuntalado por la canalización de importantes flujos de inversión pública para crear la 
industria petroquímica. En este tiempo se construyó el Complejo Cosoleacaque, con siete plantas industriales que comenzaron a funcionar en 1962; el Complejo La Cangrejera inició operaciones en 1980 con 20 plantas; y las ocho plantas industriales del Complejo Morelos se echaron a andar en 1988 (Sánchez et al., 1999). Según un analista, tan sólo la construcción de La Cangrejera permitió, en la década de 1970, la contratación de 17000 personas al mismo tiempo en los momentos de mayor demanda laboral (Romero, 1998).

Los indígenas de diversas localidades de la Sierra de Santa Marta, donde se vivía una serie de reacomodos sociales como consecuencia del reparto agrario que había tenido lugar en la primera mitad de la década de 1960, así como del posterior acaparamiento de tierras ejidales para la expansión de la ganadería bovina (Velázquez, 2000 y 2006), no fueron inmunes a esta demanda de mano de obra. La noticia de que había trabajo para todo el que quisiera emplearse en las empresas de PEMEX se extendió por los diferentes poblados de la Sierra y muchos campesinos dedicados al cultivo de productos básicos se decidieron a probar suerte en las ciudades con la esperanza de mejorar sus condiciones económicas.

[En las tierras del ejido Soteapan] sembraba yo maíz, sembraba yo frijol, y nada más esas dos cosas lo sembraba yo porque no hay otra [...] [Lo que] yo sembraba pues no era mucho porque nada más sembraba hasta donde la fuerza alcance, nomás tres hectáreas, y de ahí mismo sacaba pa' comer y de ahí mismo sacaba pa'l gasto pero la verdad es que con varios hijos no alcanzaba yo a mantener[los] con lo que yo cosechaba, mi cosecha no me daba [...] por eso me fui a trabajar a esos lugares. [...] La primera vez yo fui porque supe que ya hay trabajo. De aquí [San Pedro Soteapan] me embarqué [en camión de pasajeros] y llegué a Coatza en la tarde, llegué al centro y pregunto cómo ir a las fábricas. Ya me contesta el señor: de aquí agarras el carro que va pa' Villahermosa y ahí le dices [al chofer] que bajas en Cangrejera. No, en ese tiempo llegas y trabajas, cualquiera que llega trabaja. ${ }^{9}$
Para una parte de la población indígena de la Sierra de Santa Marta, la demanda de mano de obra para la construcción de los complejos petroquímicos representó su primera experiencia migratoria, la cual en esta época tuvo la particularidad de ser intrarregional, lo que les permitía mantener una relación constante con sus lugares de origen, a donde regresaban cada fin de semana. A esta migración recurrieron los campesinos con mayores carencias económicas, ya fuera porque carecían de tierra, o porque éstas eran poco productivas por la mala calidad del terreno, o porque el uso de una tecnología rudimentaria sólo les permitía sembrar un máximo de dos o tres hectáreas, o porque las tierras a las que tenían acceso se ubicaban en lugares donde no era posible desarrollar cultivos comerciales como el café o introducir ganado.

Así, la migración hacia Coatzacoalcos no tuvo la misma intensidad en toda la sierra: fue más abundante en la cabecera municipal de Mecayapan — nahua-y en varias de sus localidades cercanas, que en la cabecera del municipio de Soteapan - popolucas - y sus poblados aledaños, en donde el acceso comunal a las tierras ejidales y la caficultura fungieron como diques a la migración:

Bueno, aquí nosotros popolucas, de aquí íbamos como cien, no muchos, no todos, y de los nahuas ellos están jodidos, iban más [...] De San Fernando (localidad cafetalera) también iban pero no muchos, los que más trabajaron, los que [...] así fueron todo ese tiempo, [eran de] por Tatahuicapan, por Mecayapan. Aquí [en Soteapan] pues no, aquí tienen tierra donde trabajar, pues no les apretaba mucho la necesidad y podían hacer más milpa. ${ }^{10}$

Sin embargo, en la década de 1980 las compañías constructoras que trabajaban para PEMEX empezaron a reducir la demanda de mano de obra. Además, la inflación que hubo después de la crisis económica nacional de 1982 hizo que el trabajo en las ciudades dejara de ser una opción económica para los campesinos: 
[Del trabajo] nunca me sacaron, ahí salí ya porque el gasto no me alcanzaba pues tengo muchos hijos, cinco hijos, y [los] mantenía con puro mi salario pequeño que ganaba yo, apenas me daba pa' mal vivir, apenas me daba pa' mal comer. Entonces ya me salí de plano porque ya no me alcanzaba, porque mis hijos estudiaban [...] ya no me daba y entonces dije no, ya no aguanto, ya hasta aquí [...] Ya cuando regresé, empecé a sembrar de nuevo."l

Estas restricciones en el mercado laboral urbano fueron paliadas de diversas maneras al interior de la región. Hubo campesinos que aprendieron oficios que les permitieron seguir combinando el trabajo agrícola con el urbano, como don José Bautista, ejidatario de Tatahuicapan, quien a la par de sembrar maíz en su parcela viajaba a Coatzacoalcos dos o tres días a la semana para hacer trabajos de electricista por cuenta propia. ${ }^{2}$ En otros casos, el acceso comunal a las tierras ejidales, que por esos años prevaleció en varios ejidos del municipio de Soteapan, permitió a los campesinos dejar los trabajos urbanos, regresar a sus localidades y volver a sembrar en tierras ejidales, aun cuando no fueran ejidatarios. ${ }^{13}$

Además, en la década de 1980 los ejidos de la parte occidental del municipio de Soteapan aumentaron su producción de café gracias a los apoyos técnicos y financieros proporcionados por el Instituto Mexicano del Café (INMECAFE), organismo paraestatal que empezó a operar en la Sierra en 1975. La superficie con cafetales pasó de 1081 hectáreas en 1969, a 2652 hectáreas en 1984 (Velázquez, 2006: 379), lo que favoreció que en la década de los años ochenta campesinos de diversas localidades de los municipios de Soteapan y Mecayapan tuvieran una opción de trabajo asalariado durante los meses de cosecha del café - diciembreenero-

Otra fuente de trabajo intrarregional a la que recurrieron principalmente campesinos del municipio de Mecayapan fue La Perla del Golfo, una próspera colonia ganadera ubicada en la parte septentrional de la sierra:
Aquí tenemos la necesidad de trabajar en el jornal, vamos a Zapotitlán, Zapoapan ${ }^{14}$ y La Perla [del Golfo] a chapear potreros. La gente se lleva sus tortillas para dos semanas y ahí se puede pescar camarón y pescado para hacerse uno su comida. Dormimos en los ranchos de los ganaderos. A Minatitlán hay gente de aquí que ha ido a trabajar como ayudante de albañil, pero no conviene ir para allá porque todo tienes que pagar: comida, pasajes, hospedaje. ${ }^{15}$

Sin embargo, estas fuentes de empleo al interior de la Sierra de Santa Marta comenzaron a debilitarse a principio de la década de 1990 debido a la drástica caída de los precios del café que inició en 1989, a la que pronto se sumó la pérdida de apoyos para la comercialización de este grano. Al mismo tiempo, los ganaderos de La Perla y otras localidades cercanas comenzaron a expandir el uso de herbicidas, con lo que la demanda de jornaleros para el chapeo manual de potreros disminuyó:

He ido algunas veces a trabajar a La Perla pero sé que este año no hubo mucho trabajo pues se está usando mucho herbicida para matar la maleza de los pastizales, así que ahora sólo hay trabajo para cultivar chile. ${ }^{16}$

Antes iba a trabajar a San Fernando, a cortar café. Salía de San Pedro [Soteapan] a las tres de la mañana, allá trabajé cinco años, puro cortar café, después ya no fui más porque ya no sale la cuenta pues se camina mucho y pagan muy barato. ${ }^{17}$

A la par que se perdían las pocas opciones de trabajo al interior de la sierra, el mercado de trabajo urbano sufría una profunda contracción a causa del proceso de reconversión de la industria petrolera y su reestructuración laboral. Bajo estas condiciones, para 1993 la ciudad de Coatzacoalcos - centro rector del Istmo veracruzano- registró una tasa de desempleo del 6.6\%, la segunda más alta del país, ${ }^{18}$ y para 1995 el desempleo aumentó a $9.8 \% .^{19}$

En varias notas periodísticas de la época quedó el registro de la pérdida de empleos urbanos. A mediados 
de 1994, PEMEX informaba que el complejo petroquímico Cosoleacaque desmantelaría dos de sus plantas de producción, por lo que cancelaría más de 120 plazas. Los trabajadores transitorios fueron los más afectados por esta situación, ya que PEMEX, según denunciaba el diputado federal por el distrito de Minatitlán, había despedido a más de 2500 de ellos (Lastra, 1994). Tres años después, el dirigente del Movimiento Nacional Petrolero afirmaba que "De los 120000 trabajadores despedidos en losúltimos ocho años, unos 40000 petroleros pertenecen a los complejos petroquímicos asentados en el sur de la entidad veracruzana." ${ }^{20}$ En 1998, los periódicos estatales seguían documentando el problema del desempleo en el sur de Veracruz, el cual afectaba a otras fuentes de trabajo, como las industrias hotelera y restaurantera. ${ }^{21}$

También el sector agropecuario sufrió las consecuencias de la desregulación económica. Así, al desplome del precio del café que tuvo lugar en el ciclo 1989-1990, se sumó el cierre del INMECAFE en 1992;22 luego vino la desaparición de los precios de garantía de los cultivos básicos en 1993; y en 2003 inició la liquidación del Banco Nacional de Crédito Rural (BANRURAL), el cual en la década de 1990 había canalizado créditos para engorda de ganado en varios ejidos de la Sierra de Santa Marta.

Fueron estas condiciones económicas las que empujaron a jóvenes nahuas y popolucas de la Sierra de Santa Marta a insertarse en nuevos mercados de trabajo, generalmente fuera de la región. En los pueblos que entonces yo visitaba para indagar sobre su historia agraria, empecé a registrar en mi cuaderno de campo datos como los siguientes:

[Ejido San Fernando] dos hermanos de Silvia y Rosa se fueron a Puerto Vallarta para alistarse en el ejército; [ejido Santa Marta] dos hijos de Eusebia y Miguel acaban de irse a Puerto Vallarta para integrarse al ejército; [Soteapan] el hijo (15 años) de Minerva se fue este año a trabajar en las maquiladoras de Ciudad Juárez, Chihuahua. ${ }^{23}$

De esta manera comenzaba la migración de nahuas y popolucas de la Sierra de Santa Marta hacia tres destinos diferentes: Puerto Vallarta, para ingresar al ejército; la frontera norte de México, para trabajar en la industria maquiladora de exportación; y la región centro-norte del estado de Sinaloa, para contratarse como jornaleros agrícolas en el cultivo de hortalizas de invierno. A la par, terminaba una migración caracterizada por su complementariedad con la agricultura y la movilidad de corta distancia, ya fuera al interior de los mismos municipios o a otras regiones del Sotavento, una migración que había estado "contenida en los espacios próximos" (Del Rey y Quesnel, 2006: 429) y de la que participaron casi exclusivamente los hombres.

\section{La frontera norte de México: la expansión y contracción de la industria maquiladora de exportación}

\section{La conformación del mercado de trabajo de las maquiladoras}

La industria maquiladora de exportación comenzó a desarrollarse en 1965 a través del Programa de Industrialización Fronteriza, cuyo objetivo fue fomentar la apertura de plantas maquiladoras para disminuir la presión sobre el mercado de trabajo fronterizo causada por el término del Programa Bracero (1942-1964). Esta industria tuvo mayor impulso a mediados de la década de 1970, cuando el gobierno federal echó a andar el Programa Nacional Fronterizo y el Programa de Comercialización Fronteriza. En la década de 1980, en el marco de los procesos de ajuste macroeconómico y de la devaluación del peso, la industria maquiladora de exportación se consolidó como el principal generador de empleo fronterizo, aprovechando las ventajas competitivas que le representaba ubicarse en la frontera norte de México, en colindancia con el mayor mercado del mundo y la disponibilidad de abundante mano de obra. En estos años, los estados fronterizos de Baja California y Chihuahua fueron los que más se beneficiaron de los estímulos gubernamentales al desarrollo industrial. Así, por ejemplo, si en 1975 el empleo en maquiladoras representó el 3.2\% del total de empleos generados en el estado de Chihuahua, para 1985 este porcentaje subió 
a $77.6 \%$ (Texis, Mungaray y Grijalva, 2009: 31-33). Tal demanda de mano de obra provocó que la inmigración se convirtiera en "un componente fundamental del crecimiento poblacional de la frontera norte mexicana" (Anguiano, 1998: 66), de forma que, según los datos del censo de población de 1990, la población inmigrante conformaba el 30\% del total de los residentes de esta región (Anguiano, 1998: 66).

La importancia de la industria maquiladora continuó en la década de 1990 y parte de la década de los años 2000, de tal manera que, entre 1994 y 2006, los seis estados colindantes con Estados Unidos - Nuevo León, Baja California, Chihuahua, Coahuila, Sonora y Tamaulipas - junto con el Distrito Federal y los estados de México, Jalisco y Puebla conformaron las diez entidades con mayores montos de inversión extranjera (Anguiano, 1998: 37). La expansión de la industria maquiladora de exportación ha estado ligada a un proceso de relocalización del gran capital mediante su traslado a territorios en los que hay la posibilidad de tener mayores ventajas económicas, ya sea por la posibilidad de obtener mano de obra barata, o porque puede aprovechar ventajas asociadas a la infraestructura existente y al capital humano o de conocimiento disponible, lo que permite mayores tasas de ganancia y competitividad (Barajas, 2009: 47). En 2005, la actividad maquiladora en los estados de Baja California, Tamaulipas y Chihuahua generaba tres cuartas partes del empleo industrial y la presencia de esta industria seguía siendo "un imán de corrientes migratorias" (Barajas, 2009: 43).

Integración tardía de los jóvenes indígenas de la Sierra de Santa Marta al mercado de trabajo de las maquiladoras

La migración hacia la industria maquiladora de exportación en la frontera norte del país fue variando con el tiempo. Sussan Vallentin (2007: 234) indica que inicialmente los trabajadores requeridos por la industria maquiladora de exportación provinieron del mismo estado de Chihuahua; después, las maquiladoras atrajeron población de Durango, Coahuila y Zacatecas; y a partir de 1995, al disminuir la migración proveniente de estos lugares, inició el desplazamiento de trabajadores desde el sureste del país. Esta tendencia ha sido registrada en la Encuesta sobre Migración en la Frontera Norte de México; según esta fuente, entre marzo de 1993 y marzo de 1994 arribaron a la frontera norte un estimado de 1799263 emigrantes laborales procedentes del sur del país, la mayoría de los cuales - 1 001 335tenía como objetivo final laborar en la frontera norte (Anguiano, 1998: 67).

En el caso del Istmo veracruzano, los primeros migrantes hacia Ciudad Juárez salieron entre 1995 y 1996, viajando primero por tren y, una vez que Ferrocarriles de México suspendió el servicio de transporte de pasajeros, se aventuraron en camión hasta la Ciudad de México, donde tenían que trasladarse de la estación camionera del oriente a la del norte, exponiéndose a engaños y robos por parte de taxistas y delincuentes que los acechaban en las terminales de autobuses (Vallentin, 2007: 174-175).

Ante el incremento de migrantes del Istmo veracruzano a la frontera norte, a finales de la década de 1990 comenzaron a aparecer en diferentes ciudades del Istmo - Chinameca, Oteapan, Jáltipan, Cosoleacaque - pequeñas agencias de viajes que vendían boletos directos a Ciudad Juárez, Chihuahua; Ciudad Acuña, Coahuila, y Reynosa, Tamaulipas. Esto facilitó que más jóvenes, tanto hombres como mujeres, se animaran a probar suerte en la industria maquiladora de la frontera norte.

Fue el caso de José Antonio, un joven de Mecayapan que viajó a Ciudad Juárez en 1998, cuando tenía 21 años y había terminado de estudiar el telebachillerato. Dos muchachos de Mecayapan, quienes ya tenían familiares trabajando en aquella ciudad, le contaron sobre las posibilidades de trabajo en las maquiladoras y le informaron que los jueves salía de la cercana ciudad de Oteapan un camión rumbo a aquella ciudad. José Antonio compró su boleto y viajaron juntos él y otros dos muchachos de Mecayapan: el resto de la gente que iba en el camión era de Oteapan y otros pueblos de la región. José Antonio narra que el transportista les ofrecía hospedaje por 15 días, y una vez que cobraban su primera quincena le pagaban el alquiler. Después, lo 
común era que varios trabajadores del mismo pueblo alquilaran algún cuarto o casa, donde llegaban a vivir 10 o 15 personas.

José Antonio recuerda que en esa época era fácil conseguir trabajo pues casi todas las maquiladoras ofrecían contrataciones inmediatas. El viaje duraba tres días: salían de Oteapan un viernes y llegaban a Ciudad Juárez el domingo; el lunes salían a buscar trabajo y prácticamente el mismo día encontraban empleo. Él empezó a trabajar en Arneses de Juárez, donde ganaba 300 pesos a la semana. En este lugar laboró sólo tres meses y como no le gustaron las condiciones de trabajo buscó otro empleo pues "allá te podías cambiar de trabajo cuando quisieras." Dejó de trabajar en Arneses porque en este lugar no se podía trabajar horas extras, lo cual necesitaba hacer para cubrir todos sus gastos de manutención, incluida la renta. Se fue a trabajar entonces a la fábrica de dulces Blueberry, donde ganaba 450 pesos por semana en la empacadora de la empresa. En este trabajo se quedó alrededor de ocho meses y se fue porque "el trato no era agradable" y la comida que les vendían "era de mala calidad." Se cambió entonces a Motores Eléctricos y allí se quedó alrededor de año y medio con un sueldo de 450 pesos por semana. En 2001 decidió regresar a Mecayapan, donde permaneció tres años; con los ahorros que juntó de su trabajo en Ciudad Juárez puso un negocio de ropa en el tianguis del pueblo. ${ }^{24}$

Estos primeros migrantes tuvieron una experiencia relativamente exitosa en Ciudad Juárez, en términos de la facilidad para encontrar trabajo, para cambiarse de maquiladora cuando algo no les gustaba o para mantener su empleo durante varios años. Y si bien necesitaban trabajar horas extra para cubrir sus necesidades de hospedaje y comida, también podían ahorrar algo.

\section{La contracción del mercado de trabajo en la frontera norte}

Los migrantes que se fueron a Ciudad Juárez hacia la mitad de la década de los años 2000 ya no tuvieron las mismas condiciones de trabajo que las narradas por María del Carmen — Soteapan- y José Antonio -
Mecayapan-. Algunos de los autores que han analizado el desarrollo de la industria maquiladora de exportación indican que esta industria comenzó a experimentar una crisis como consecuencia de la recesión que desde 2001 empezó a enfrentar la economía estadounidense (Barajas, 2009: 67; Hualde, 2008: 33-34). Esta vez, la crisis de la industria maquiladora de exportación, con su consecuente contracción de demanda de mano de obra, era diferente a las crisis cíclicas que en el pasado había enfrentado, ocurriendo ahora una especie de pérdida de crecimiento a largo plazo (Barajas, 2009: 67). Lo que esta crisis muestra es que, frente a China y Centroamérica, México no ha tenido la suficiente capacidad para atraer capital extranjero en las cadenas de subcontratación internacional en las que se inserta la industria maquiladora de exportación (Grijalva y Zúñiga, 2009: 228).

Pese a este contexto, Ciudad Juárez ha sido el centro maquilador menos afectado en cuanto a establecimientos industriales frente a Mexicali y Tijuana, que sufrieron los efectos más graves. Sin embargo, con relación al empleo, las tres ciudades tuvieron un crecimiento negativo que se ubicó en promedio en -2.5\% anual (Grijalva y Zúñiga, 2009: 228). De esta manera, al finalizar 2005 en el país operaba un número de maquiladoras similar al que había en 1997 y 1998 (Grijalva y Zúñiga, 2009: 229), lo que muestra el estancamiento en el crecimiento de esta industria.

Esta contracción de la industria maquiladora de exportación ha sido una de las dos causas principales aducidas por varias de las personas entrevistadas en Mecayapan y Mirador Saltillo sobre los motivos por los cuales han regresado a vivir a sus poblaciones de origen; la otra causa por la que los entrevistados decidieron no seguir en Ciudad Juárez ha sido el miedo a la creciente violencia de los últimos años de la primera década del siglo XXI, tal como se expresa en los siguientes extractos de entrevistas que hacen referencia a estas dos condiciones.

Joel tenía 19 años y estudios completos de bachillerato cuando en 2003 salió de Mecayapan para irse a trabajar a Ciudad Juárez, lugar en el que ya vivían unos primos suyos, quienes lo ayudaron a buscar trabajo pues ellos 
conocían las maquiladoras que buscaban obreros. Entró a laborar en una empresa dulcera, en la que trabajó cuatro años, hasta que la empresa liquidó a sus trabajadores y cerró sus puertas. Joel ya no buscó un nuevo trabajo; prefirió regresar a Mecayapan porque la delincuencia crecía aceleradamente,

[...] cada día uno escuchaba noticias de muertes, asaltos y secuestros [...] Uno vivía con una gran inseguridad, ya fuera que saliera uno a trabajar o a caminar un rato en un parque, de igual forma si uno iba a surtirse de despensa en un centro comercial o mercado, entonces es la amenaza que vivía día a día." ${ }^{25}$

Una experiencia similar de desempleo vivieron quienes se fueron a trabajar a Ciudad Acuña, Coahuila. Gelasio, un joven nahua de Mecayapan, se fue a aquella ciudad fronteriza en 2000, cuando tenía 18 años de edad y había concluido el telebachillerato; llegó a vivir con una hermana que se había ido a Ciudad Acuña en 1995. A Gelasio le llevó 15 días conseguir trabajo en una fábrica de frenos de aire, donde permaneció siete meses y después buscó otro empleo mejor pagado. Se cambió a una fábrica de arneses para automóviles en la que trabajó ocho años, hasta que lo liquidaron por una política de reducción de personal. Regresó a Mecayapan en 2009. ${ }^{26}$

En suma, la mayoría de los migrantes de retorno que entrevistamos en varias localidades de la Sierra de Santa Marta había ido a Ciudad Juárez por primera vez durante la época en que ya había iniciado la contracción de la industria maquiladora de exportación, pese a lo cual todos encontraron trabajo, aunque también enfrentaron con regularidad el cierre de las empresas en las que laboraban. Tal vez esta inserción tardía a la migración a Ciudad Juárez explique una diferencia central con lo reportado por Vallentin (2007: 178-179) para la migración Oteapan-Ciudad Juárez. ${ }^{27}$ De acuerdo con lo investigado por esta autora, en la primera etapa de la migración (1995-1997), desde Oteapan salieron hombres solos que una vez establecidos en Ciudad Juárez mandaron traer a su familia nuclear, de tal manera que después de 1997 "comenzaron a trasladarse familias enteras hacia la frontera," para después llevarse a parientes consanguíneos y políticos.

En cambio, la mayoría de los migrantes de retorno que entrevistamos en Mecayapan, Soteapan y Mirador Saltillo eran hombres y mujeres jóvenes solteros que llegaron a vivir a Ciudad Juárez con hermanos o primos jóvenes, algunos también solteros y otros recién casados. Los migrantes nahuas y popolucas que entrevistamos se habían ido a Ciudad Juárez y Ciudad Acuña con edades entre 18 y 21 años, sin experiencias previas de trabajo asalariado, en tanto que algunos de los migrantes de Oteapan entrevistados por Vallentin (2007: 176) en Ciudad Juárez tenían entre 35 y 41 años y contaban con experiencia como asalariados en la ciudad de Minatitlán.

Por otro lado, la mayoría de los migrantes de retorno entrevistados en Mecayapan, Mirador Saltillo y Sotepan había concluido la secundaria o la preparatoria, e incluso uno tenía una carrera universitaria. Ellos eran parte de la primera generación de jóvenes indígenas que tuvieron acceso a la educación secundaria y de bachillerato en sus propias localidades o cabeceras municipales. ${ }^{28} \mathrm{Sin}$ embargo, sus mayores niveles de escolaridad no se expresaron en mejores ventajas laborales en su región de origen, donde la economía industrial y agropecuaria había perdido el vigor que había tenido en décadas anteriores, lo que les obligó a buscar nuevos mercados laborales fuera de la región. En un estudio realizado en 1999 mediante la aplicación de una encuesta aleatoria a 947 familias en el sur de Veracruz, Del Rey y Quesnel (2006: 443) encontraron que el nivel educativo aparecía como el principal condicionante para migrar a la frontera norte, ya que para ser contratado en las maquiladoras debían saber leer y escribir.

Así, muchos de los jóvenes escolarizados de la Sierra de Santa Marta, al enfrentar la carencia de fuentes de empleo en la región, decidieron probar suerte en Ciudad Juárez o Ciudad Acuña. Para la gran mayoría de ellos, éste era su destino final de trabajo, según expresaron en las entrevistas realizadas en 2010 y 2011, cuando estaban ya de regreso en sus lugares de origen. Esto concuerda con los resultados de la Encuesta sobre Migración en la Frontera Norte de México aplicada en los años 1993-2003 
por El Colegio de la Frontera Norte (COLEF) (Anguiano, 2005: 102). La mayoría de los emigrantes veracruzanos entrevistados por el COLEF en estos años no tenía la intención primaria de cruzar a Estados Unidos, de tal manera que entre el $76.3 \%$ y el $88.5 \%$ constituían un flujo de migración mayoritariamente interna (Anguiano, 2005: 102).

Otro aspecto a resaltar es que los ahorros de los emigrantes de Mecayapan, Mirador Saltillo y Soteapan fueron mínimos; sólo uno de los entrevistados pudo construir su casa, otros únicamente pudieron adquirir el material de construcción, y algunos iniciaron la construcción pero no la terminaron. También hubo quienes no lograron construir su casa debido a imprevistos relacionados con la solución de problemas de salud personales o familiares. Uno de estos migrantes se refería en los siguientes términos a la incapacidad de ahorrar: "lo que ganas allá, allá mismo te lo gastas en comer y pagar renta." ${ }^{29}$

Finalmente, a todos los entrevistados les preguntamos si tenían intenciones de volver a Ciudad Juárez y la respuesta fue tajantemente negativa. Señalaban que, además de las dificultades que ahora existían para conseguir trabajo o para conservarlo por varios años, les atemorizaba el clima de violencia que se había acrecentado en los últimos años de la década de los 2000. No es que antes no hubiera un ambiente de violencia, sobre todo hacia las mujeres, ${ }^{30}$ pero era manejable mediante ciertas estrategias, como no hablar con desconocidos, no salir a lugares de diversión nocturna, ir directo del trabajo a sus casas o pasear los domingos en compañía de familiares. ${ }^{31}$ Desafortunadamente, no existen datos precisos sobre la magnitud del retorno obligado de los trabajadores del Istmo veracruzano que laboraban en las ciudades fronterizas; y si bien es cierto que muchos de estos migrantes decidieron regresar a sus lugares de origen, otros más han preferido permanecer en la frontera.

Desgraciadamente, carecemos de cifras precisas o siquiera aproximadas sobre el número de trabajadores de esta región que permanecen trabajando en las maquiladoras fronterizas, o que en lugar de regresar a sus pueblos veracruzanos han decidido dirigirse a los
Estados Unidos. Sin embargo, lo que resultó evidente durante la investigación de campo fue que la frontera norte se ha diluido como una opción relevante de trabajo para los jóvenes escolarizados de la Sierra de Santa Marta. Y si bien ha cobrado auge el trabajo temporal en los campos agrícolas de Sinaloa - y de Sonora en menor medida-, éste es un mercado laboral al que recurre otro tipo de migrantes, tal como veremos en el siguiente apartado.

\section{Sinaloa: auge y consolidación de la agricultura intensiva para exportación}

La producción hortícola para exportación se ha practicado en Sinaloa desde principios del siglo XX y desde entonces ha estado dirigida principalmente al mercado estadounidense. Si bien la exportación de hortalizas se interrumpió durante el periodo armado de la Revolución mexicana, pronto se recuperó de este evento. Además, la Revolución no afectó de manera inmediata a la gran propiedad privada de Sinaloa, aunque sí favoreció el surgimiento de una nueva capa de pequeños productores que adquirieron tierras de calidad para dedicarlas a cultivos de alta rentabilidad destinados tanto al mercado nacional como al internacional. Esta dinámica actividad agrícola se ha concentrado desde entonces en la región centro-norte, que abarca los municipios de Ahome, El Fuerte, Elota, Guasave y Angostura, así como parte de los municipios de Sinaloa de Leyva, Mocorito y Culiacán (Aguilar, 2001: 144).

En términos del valor de la producción, los principales cultivos en las décadas de 1920 y 1930 eran el tomate y el garbanzo, aunque también se sembraba maíz (Aguilar, 2001: 147). Esta producción agrícola sufrió una notable contracción en la segunda mitad de la década de 1930 como respuesta a las acciones del presidente de la República, Lázaro Cárdenas, de ejecutar la reforma agraria que se había pospuesto durante dos décadas. Las consecuencias de estas acciones fueron notables: en 1930, la superficie total de tierras privadas era de 97\% y sólo el 3\% correspondía a tierras ejidales, en tanto que para 1940 el 45\% de 
superficie agraria correspondía a la propiedad privada y el 55\% a la propiedad ejidal (Aguilar, 2001: 149).

Sin embargo, los gobiernos posteriores al cardenismo se concentraron en buscar la reconciliación con los grupos empresariales, implantando una política orientada a fomentar la agricultura capitalista, frenar la reforma agraria, dar seguridad a la propiedad de la tierra y apoyar a los agricultores privados. En este contexto, en la década de 1940 la agricultura comercial cobró un nuevo auge, del cual se benefició particularmente la horticultura (Aguilar, 2001: 149); al respecto, Sara Lara (1998: 164) indica que la producción de tomate en 1945 triplicó la producción obtenida a mediados de la década de 1930.

Así, los empresarios agrícolas de Sinaloa, organizados desde 1932 en torno a la Confederación de Asociaciones Agrícolas del Estado de Sinaloa (CAADES) (Aguilar, 2001: 156), se favorecieron tanto de la oportunidad que representó el trastorno en el comercio internacional producido por la Segunda Guerra Mundial, como de las prebendas derivadas de las políticas públicas de apoyo a la agricultura capitalista, particularmente durante los sexenios de los presidentes Manuel Ávila Camacho (1941-1946) y Miguel Alemán Velasco (19471952) (Hewitt, 1978: 23-24).

Un apoyo importante a la agricultura capitalista de Sinaloa fue la canalización de recursos federales a la construcción de grandes obras de infraestructura hidráulica, con lo que se crearon los distritos de riego del noroeste (Gámez, 2006). En el periodo transcurrido entre 1947 y 1952, las inversiones gubernamentales para la irrigación se concentraron de manera importante - 47\% del total invertido - en el norte y noroeste del país, en regiones con producción destinada a la exportación (López y Aguilar, 2004: 4). En el valle de Culiacán, la finalización de la construcción de la presa Sanalona en 1948 permitió la irrigación de más de 95000 hectáreas, con lo que la actividad agrícola adquirió un gran auge en esta región (López y Aguilar, 2004: 7). Así, la agricultura comercial, que desde la década de 1930 se beneficiaba con créditos bancarios, se convirtió en el eje de la estructura económica de Sinaloa (Aguilar, 2001: 190). ${ }^{32}$
Al concluir la Segunda Guerra Mundial se amplió el mercado de hortalizas en Estados Unidos gracias al crecimiento de sus ingresos per cápita. Las ventajas competitivas en costos, principalmente salariales, facilitaron que la producción de hortalizas se expandiera más en México que en Estados Unidos. Además, el bloqueo económico a Cuba por parte de Estados Unidos en la década de 1960 obligó a dedicar una mayor extensión de tierras de Florida al cultivo de caña de azúcar, sustrayéndolas a la siembra de hortalizas. También en el mercado nacional aumentó la demanda de productos agrícolas, lo cual fue aprovechado por los agricultores sinaloenses. Bajo estas condiciones de mercado, en 1960 la principal agroindustria de Sinaloa, por número de empresas (74) y valor de la producción total (36\%), era el empaque de hortalizas (Aguilar, 2001: 191).

Afinalesdeladécadade1960losproductoresde tomate de Sinaloa incorporaron tres importantes innovaciones diseñadas por agricultores estadounidenses: la construcción de invernaderos para producir plántulas a gran escala, la siembra en el campo del tomate de vara que sustituyó al tomate de piso, y la mecanización del empaque. Estos cambios permitieron pasar de una producción artesanal y rústica a otra de tipo masivo y a gran escala, lo que provocó un incremento notable de la demanda de mano de obra. También aumentaron considerablemente los costos de producción, ya que la nueva modalidad de cultivo requería la incorporación de un paquete tecnológico con insumos importados de Estados Unidos. Todo esto derivó a su vez en el surgimiento de "una tendencia a la concentración de la producción entre algunas decenas de grandes horticultores" (Lara, 1998: 164-166).

La producción masiva derivada de los cambios tecnológicos introducidos requirió, a su vez, la creación de una compleja red de comercialización y distribución del producto; ésta fue controlada por los más grandes horticultores, asociados en general a capitales estadounidenses. ${ }^{33}$ Por su parte, el gobierno mexicano apoyó el desarrollo de esta nueva fase de la agricultura de exportación del noroeste con la construcción, entre las décadas de 1970 y 1980, de una 
autopista que atraviesa los estados de Sinaloa y Sonora hasta la ciudad fronteriza de Nogales. También se ampliaron las obras de riego, el crédito y diversos subsidios gubernamentales (Lara, 1998: 167).

\section{La mano de obra indígena: un insumo necesario de la agricultura intensiva}

La mayor demanda de mano de obra en los años ochenta del siglo XX fue resuelta mediante la contratación de hombres, mujeres y niños de pueblos de Los Altos de Sinaloa, así como con población local de escasos recursos. Sin embargo, los trabajadores sinaloenses no eran suficientes durante el corte del tomate, así que los empresarios debieron organizar campañas de promoción de empleo en estados pobres del país, particularmente Oaxaca y Guerrero (Lara, 1998: 170).

En la década de 1990, los horticultores de Sinaloa enfrentaron nuevas condiciones que, como afirma Lara (1998: 179), marcaron profundamente la situación de sus empresas. En el marco del Acuerdo General sobre Aranceles Aduaneros y Comercio (GATT), que en 1986 firmó el gobierno mexicano, se comenzó a aplicar una nueva normatividad con relación al comercio internacional. En 1991 llegó a su fin la regulación de la producción a través de la concesión de permisos de siembra que otorgaba la Confederación Nacional de Productores de Hortalizas (CNPH) y la CAADES. Además, el gobierno federal retiró los subsidios a la producción, a la vez que ocurría un encarecimiento del crédito agrícola. Lara (1998: 178) también indica que estos cambios propiciaron que los cientos de pequeños productores que participaron alguna vez en el negocio de la horticultura, cedieran su lugar a algunas decenas de enormes empresas, ocho de las cuales dominaban la producción y la comercialización.

En la década de 1990, y bajo nuevas condiciones económicas nacionales e internacionales, México consolidó su participación en el mercadoestadounidense duplicando en dos años su aporte al abasto de hortalizas, pasando de cubrir el 1.6\% en 1991 al 3\% en 1993 (Gámez, 2006). Los mayores volúmenes de exportación provinieron del noroeste de México, destacando la producción invernal de Sinaloa y Sonora, estados que aportan en conjunto casi las dos terceras partes de la exportación nacional de tomate, pepino, chile, calabaza y sandía. El punto de concentración para la exportación de estas hortalizas es la frontera con Nogales, Arizona, la cual entre 1990 y 1997 experimentó un incremento del $61 \%$ en los volúmenes de cruce de estos productos (Gámez, 2006: 170).

De acuerdo con Gámez (2006: 171-173), el auge de las exportaciones hortícolas en la última década del siglo XX y la primera del XXI se explica por cuatro acontecimientos principales: 1) las devaluaciones recurrentes del peso mexicano frente al dólar permitieron producir a bajos costos; 2) la firma del TLCAN eliminó los aranceles al melón, la sandía y el pepino, y estableció reducciones programadas en cultivos más competitivos, como tomate, cebolla, chile, berenjena y calabacita; 3) la incidencia de fenómenos naturales afectó negativamente la producción de Florida, estado en el que las heladas de mediados de la década del 2000 prácticamente terminaron con su producción invernal; y 4) la adopción de cambios tecnológicos aumentó la productividad.

La capacidad de producción y de contratación de mano de obra por parte de las principales empresas hortícolas de Sinaloa puede ejemplificarse con el caso de la Empresa Agrícola Tarriba, la cual ha establecido su propia cadena de producción, comercialización y distribución. Según el estudio que Gámez (2006) hizo de esta empresa, en sus campos de producción localizados en el municipio de Elota- laboran 10000 jornaleros agrícolas por temporada, distribuidos en cinco campos: Tayoltita, Ceuta, Bella Vista, Caimanes y Nuevo Caimanes (Gámez, 2006: 218). Parte de la fuerza de trabajo que sostiene la producción de esta empresa proviene del sur de Veracruz, principalmente del municipio de Mecayapan, y en menor medida de Soteapan.

La migración de Mecayapan a Sinaloa comenzó en 1997, cuando un contratista procedente de Minatitlán llegó al pueblo a ofrecer trabajo. Menos de diez personas se aventuraron a trasladarse a un lugar que desconocían, 
donde trabajarían con cultivos que no se practican en la sierra. Una de las personas que viajó por primera vez a Sinaloa fue Eloísa, quien entonces tenía 35 años, cuatro hijos y un esposo que por su afición al alcohol, y en un contexto local de escasa oferta de trabajo, no proveía el suficiente dinero para mantener a su familia, así que "un día comíamos y otro no." Eloísa llevó con ella a una hermana soltera, un hijo de 12 años y un bebé de año y medio; a sus otras dos hijas, de ocho y tres años, las dejó al cuidado de su madre. ${ }^{34}$

El contratista que llevó a estos primeros migrantes de Mecayapan trabajaba para Agrícola Bon. Esta primera experiencia fue dura para Eloísa por dos razones: en el pueblo empezaron a hablar mal de ella, a decir que por las noches se iba con hombres que trabajaban en el mismo campo; pero lo principal fue que su pequeña hija no estaba acostumbrada a tomar leche en biberón, así que debía llevársela al campo cargándola en su espalda para poder alimentarla, lo que volvía extremadamente duro su trabajo. Por ésta y otras razones, un mes y medio después de llegar a Sinaloa debieron regresar, lo cual lamentó pues allá ganaba 192 pesos a la semana, mientras que en Mecayapan su esposo le daba entre 30 y 50 pesos a la semana para los gastos familiares.

Un año después, en octubre de 1998, Eloísa volvió a irse a Sinaloa pero esta vez con toda la familia, incluido su esposo; también iba su hermana y el esposo de ésta. Recuerda que en el camión que los llevó a Sinaloa viajaban nahuas de Huazuntlán, un poblado perteneciente al municipio de Mecayapan; en ese año todavía no iba mucha gente de Mecayapan, "pues les daba miedo irse tan lejos." En esta ocasión, el contratista procedía de Coatzacoalcos y los llevó a trabajar al campo San Rafael, propiedad de la familia Clouthier. Un mes después de llegar a Sinaloa, un dirigente del sindicato de jornaleros agrícolas le propuso a Eloísa que regresara a Mecayapan a conseguir más trabajadores para el corte de ejote, chile y tomate. Eloísa aceptó y regresó a Mecayapan en un camión que le proporcionó la empresa; en dos días logró juntar a 38 jornaleros, labor por la cual recibió 500 pesos de compensación. Eloísa y su familia trabajaron en el campo San Rafael entre 1998 y 2001.
Muy pronto otros pobladores de Mecayapan se iniciaron en la migración y en la labor de contratistas. Efraín, por ejemplo, viajó por primera vez a Sinaloa en el año 2000, cuando tenía 17 años; tres años después empezó a trabajar como contratista para la compañía Agrícola Primavera. En 2010, Efraín aseguraba que cada año llevaba a La Primavera tres camiones con jornaleros, tanto de Mecayapan como de otros poblados de este municipio y del vecino Tatahuicapan. ${ }^{35}$

Actualmente, en Mecayapan existen alrededor de 20 contratistas cuya labor es reclutar trabajadores para las diferentes empresas agrícolas de Sinaloa. En el mes de julio, los contratistas empiezan a recibir en sus casas la visita de los trabajadores que irán con ellos y los incluyen en listas; también acuden a otras localidades para anunciar las próximas contrataciones. En este tiempo, los contratistas deben estar en contacto telefónico con las empresas de Sinaloa para conocer el número de trabajadores que requerirán y acordar las fechas en las que deberán partir hacia Sinaloa. También reúnen la documentación necesaria para tramitar, ante la delegación Coatzacoalcos de la Secretaría del Trabajo, el apoyo económico que desde el año 2002 el gobierno federal otorga a cada trabajador para que cubra parte de los gastos que realiza durante el viaje a Sinaloa, el cual dura tres días. ${ }^{36}$

El contratista que lleva dos o tres camiones con trabajadores solicita a uno o dos conocidos o familiares de confianza que sean sus ayudantes. Cada uno se hace cargo de un camión, los cuales parten de Mecayapan en forma escalonada, según lo vaya requiriendo la empresa. Generalmente, los primeros camiones con jornaleros salen de Mecayapan en el mes de agosto y los últimos se van en noviembre, para regresar al siguiente año entre mayo y junio. El contratista que lleva más de un autobús con jornaleros viaja en el último camión que sale de Mecayapan, pues debe vigilar que vayan todos los trabajadores que se apuntaron con él.37

El contratista y sus ayudantes deben hacerse responsables del viaje, lo cual implica estar pendientes de que el chofer atienda las necesidades de los viajeros, como detener el autobús periódicamente para que éstos y los niños que los acompañan vayan al baño, o 
compren algo de comer o beber. También se ocupan de llamar a los encargados de las empresas contratantes en caso de que tengan algún percance durante el viaje, entre los que sobresalen las descomposturas de los viejos camiones que las empresas alquilan para ir por los jornaleros. ${ }^{38}$

Una vez que llegan a los campos agrícolas, los contratistas son empleados como mayordomos y el resto de las personas como jornaleros, con horarios de 7 a.m. a 4 p.m. en algunos campos o de 7 a.m. a 5 p.m. en otros. Cada día los contratistas reciben instrucciones del ingeniero o del mayordomo general del campo acerca de las labores que deben realizar los trabajadores. El mayordomo se encarga de ordenar a su gente lo que tiene que hacer, así como de vigilar que el trabajo se realice de acuerdo a las indicaciones recibidas. ${ }^{39}$

A diferencia de los migrantes a la frontera norte, entre los primeros jornaleros agrícolas que se fueron a Sinaloa abundaban las personas mayores, muchas de las cuales trabajaban como jornaleros en sus mismos poblados o en lugares cercanos. Bonifacio, por ejemplo, es un hombre nahua que fue por primera vez a Sinaloa en 1999, cuando tenía 44 años. Se fue con un sobrino que se desempeñaba como contratista en la empresa Tarriba. ${ }^{40}$ Gaudencio es otro nahua de Mecayapan que también se fue a Sinaloa por primera vez en 1999, cuando tenía 45 años; en 2007 dejó de ir a Sinaloa porque se sentía cansado, pero sus hijos y nueras siguen viajando cada año. ${ }^{41}$

La migración familiar es otra particularidad del trabajo en Sinaloa que la diferencia de la migración a la frontera norte pues a Sinaloa se trasladan familias completas, ya sean nucleares - padres e hijos-o ampliadas - padres, hijos, suegros, hermanosEn 2010, cuando entrevisté a Bonifacio, este hombre viajaría, como lo había hecho en años anteriores, llevando consigo a su esposa, seis hijos y las esposas de éstos. Éste sería el último año que Bonifacio migraría pues había cumplido la edad límite que desde 2009 pusieron las empresas agroexportadoras para contratar jornaleros, además de que se sentía cansado. ${ }^{42}$ Efraín, un contratista de Mecayapan, en 2010 iría a Sinaloa, igual que otros años, acompañado por sus padres, su esposa, cuatro hermanos y dos cuñadas, llevando con ellos a cinco niños. ${ }^{43}$

Las familias que migran a Sinaloa se instalan en los campos agrícolas, que son lugares cerrados dentro de los cuales se encuentran las áreas de cultivo, selección y empaque de las hortalizas para exportación, así como espacios habitacionales que consisten en cuartos de lámina - uno por familia - y habitaciones para solteros —cuartos de mayor tamaño en los que se aloja a grupos de jóvenes varones sin pareja-. Dentro de estos campos se encuentran también una guardería, una escuela y una enfermería. Una nota periodística de 2011 describía en los siguientes términos la existencia de guarderías, escuelas y viviendas en dos campos agrícolas:

En los albergues de Ceuta Produce y Nuevo Caimanes se cuenta con 495 niños en guarderías subrogadas, así como 502 niños de entre cuatro y cinco años en guarderías no subrogadas. 597 niños cursan educación primaria y 179 en educación pre escolar. Entre ambos albergues existen mil 255 viviendas, donde habita una población de 5027 migrantes (Rodríguez, 2011).

El trabajo en Sinaloa propició que niños y niñas se convirtieran en protagonistas directos de la migración, al acompañar a sus padres en sus viajes anuales, lo que facilita su incorporación al trabajo asalariado una vez que llegan a la edad requerida para ser contratados. Sin embargo, esta situación empezó a cambiar en el ciclo 2009-2010, cuando algunas empresas se negaron a aceptar familias con más de dos hijos pequeños. A las madres solteras que ese año llegaron con más de dos niños "las retacharon en el mismo camión que habían llegado y que regresaba a Mecayapan por más trabajadores." ${ }^{44}$ Esto, por supuesto, obligará a hacer reajustes familiares importantes cuyas principales consecuencias seguramente recaerán en las mujeres, ya sea en las abuelas que se vean obligadas a hacerse cargo de los nietos, o en las madres de familia que no podrán ir a Sinaloa pues deberán permanecer en Mecayapan para cuidar a los hijos e hijas pequeños.

En suma, las entrevistas realizadas indican que fue a finales de la década de 1990 cuando nahuas y popolucas 
de la Sierra de Santa Marta optaron por integrarse a la migración temporal a Sinaloa, lo cual concuerda con los resultados del estudio que sobre migración interna indígena en Oaxaca, Guerrero y Veracruz realizaron Rabel, Murillo y Casellas (2007). Tomando como base los datos del Censo de Población de 2000, estas autoras encontraron que Sinaloa no figuraba entre los principales lugares de destino de los emigrantes acumulados del estado de Veracruz - aquellas personas que emigraron antes de 1995-. Sin embargo, para el año 2000 Sinaloa aparecía como uno de los lugares de destino de los emigrantes indígenas recientes de Veracruz, es decir, de aquellos que emigraron entre 1995 y 2000. En este periodo, la emigración de indígenas veracruzanos a Sinaloa representó el 6.1\%, un porcentaje superado por otros dos destinos de emigración vigentes en el año 2000: el Estado de México (21.6\%) y Tamaulipas (15.2\%). Desgraciadamente, no contamos con una investigación semejante para 2010.

Ahora bien, la migración a Sinaloa sólo permite cubrir las necesidades básicas de la subsistencia familiar, tales como construir una casa de paredes de block, piso de cemento y baño, algo a lo que no tendrían acceso si dependieran únicamente del trabajo asalariado que eventualmente se consigue en las propias localidades. Elia, una mujer de Mecayapan, recordaba así su situación antes de ir a Sinaloa "no tenía yo nada, mi casa casi ni paredes tenía." ${ }^{45}$ Por ello es que, como indicaba un contratista, "todos los que migran llevan un propósito: hacer su casa, repellarla, hacer su baño," pues las casas que tenían la mayoría de los migrantes estaban hechas con materiales precarios y sin inodoro en el solar, por lo que para satisfacer sus necesidades fisiológicas debían caminar hasta alguna zona rodeada de arbustos para defecar al aire libre.

Sin embargo, lograr la construcción de una casa conlleva mucho esfuerzo familiar, como se aprecia en el caso de Rosa, una mujer de 38 años que es contratista de jornaleros. Esta mujer viajó por primera vez a Sinaloa en 2001, junto con su esposo, un hijo de 12 años y una hija de ocho. La primera vez sólo lograron ahorrar 3000 pesos pues su esposo era afecto a las bebidas alcohólicas; con este dinero compró lámina y madera para reparar su vieja casa. Al siguiente año ahorraron 6,000 pesos y compró block; tardaron cuatro años en terminar su casa. ${ }^{47}$ Dependiendo del tipo de familia que migra - si tiene hijos menores o en edad de trabajar-, así como de los hábitos del jefe de familia — si toma o no alcoholla construcción de una casa podrá hacerse con dos años de trabajo como mínimo, o seis como máximo. En todos los casos, los ahorros que los migrantes traen de regreso a sus localidades no se destinan exclusivamente a la construcción de casas, ya que una parte se ocupa para la manutención de la familia durante los tres o cuatro meses que permanecen en sus pueblos antes de partir nuevamente hacia Sinaloa.

\section{Reflexiones finales}

En este texto he buscado mostrar que en la etapa actual deglobalización económica han adquirido relevancia dos procesos entrelazados: la relocalización de actividades productivas y una importante transformación en los patrones de movilidad de la población. He demostrado también cómo una región otrora próspera, tanto en términos de su producción agropecuaria como industrial, ha sucumbido a los efectos de las políticas neoliberales sin que sus élites económicas y políticas hayan sido capaces de construir alternativas de producción y empleo.

A diferencia de otras regiones del país, en las que se han conjuntado esfuerzos gubernamentales y privados para incorporarse a las nuevas demandas del mercado, ${ }^{48}$ el Istmo veracruzano parece seguir apostando por una reactivación de la actividad petrolera que no parece llegar con la contundencia necesaria, en tanto que la actividad agropecuaria sobrevive con escasos apoyos financieros y técnicos. Imágenes elocuentes de esta situación son varias instalaciones ligadas a la actividad agropecuaria en Acayucan, cuyo abandono puede apreciarse en la maquinaria oxidada que se observa a través de los vidrios rotos de las ventanas de sus fachadas. ${ }^{49}$

En estas condiciones, los trabajadores del Istmo veracruzano han tenido que buscar opciones de trabajo en lugares lejanos: Estados Unidos, la frontera norte y los 
campos agrícolas del noroeste. La población indígena de la Sierra de Santa Marta ha recurrido a los tres destinos, aunque han sido estos dos últimos los predominantes. De esta manera, campesinos provenientes de una agricultura técnicamente rudimentaria se han transformado en jornaleros agrícolas de empresas dedicadas a la agricultura intensiva para exportación, a la vez que jóvenes campesinos o hijos de campesinos se han convertido en obreros de maquiladoras en ciudades fronterizas.

Por otro lado, estos campesinos e hijos de campesinos han hecho nuevos aprendizajes técnicos, ya sea en la agricultura o en la industria automotriz o electrónica, pero también nuevos aprendizajes socioculturales que han ido desde adaptarse a la vida urbana hasta escuchar hablar de derechos sociales que no eran parte de su repertorio sociocultural. También han tenido que aprender nuevos códigos de conducta, particularmente aquellos relacionados con la vida en medios con altos niveles de violencia. En un futuro quizás no lejano estos nuevos aprendizajes tendrán necesariamente repercusiones locales de diverso tipo.

En conclusión, la migración interna ha facilitado que pobladores indígenas del Istmo veracruzano, dedicados principalmente al cultivo de granos básicos y a una ganadería ejidal de pequeña escala, hayan pasado a formar parte de lógicas e intereses trasnacionales que están presentes en la reconfiguración misma de la localidad, donde ahora la migración es un referente obligado en la planeación de las actividades familiares, pero también en el imaginario colectivo, en el que Sinaloa o la frontera norte son concebidos e imaginados de diferentes maneras dependiendo de la posición económica y sociocultural que se ocupe en cada poblado.

\section{Notas}

${ }^{1}$ Este trabajo se realizó en el marco de un proyecto internacional -TRANSITER - que involucró a investigadores mexicanos adscritos al CIESAS Golfo - Hipólito Rodríguez y Emilia Velázqueze investigadores franceses de la Universidad Paris
Diderot — Laurent Faret, coordinador general, Aurélia Michel y Delphine Prunier-. Tanto en campo como en seminarios internos, los miembros del equipo mexicano contamos con la asesoría científica del Dr. André Quesnel (IRD), así como con el apoyo del maestro Rafael Palma y del sociólogo Gilberto Cházaro. En el caso de una parte de las entrevistas realizadas en Mecayapan, y en la casi totalidad de entrevistas levantadas en Mirador Saltillo, conté con la ayuda invaluable de la Lic. Pilar Hernández, nahua hablante de Mecayapan. La versión final de este artículo se benefició de los comentarios y sugerencias de dos dictaminadores anónimos.

2 Información aparecida en el Diario Eyipantla, 20 de noviembre de 2010; Milenio Diario, 25 de marzo de 2010; y Diario de Xalapa, 25 de marzo de 2010.

${ }^{3}$ La Jornada Veracruz, 8 de agosto de 2011.

${ }^{4}$ El Istmo veracruzano se localiza en la cuenca del río Coatzacoalcos y comprende los municipios de Acayucan, Coatzacoalcos, Cosoleacaque, Chinameca, Las Choapas, Hidalgotitlán, Hueyapan de Ocampo, Ixhuatlán del Sureste, Jáltipan, Jesús Carranza, Mecayapan, Minatitlán, Moloacán, Oluta, Oteapan, Pajapan, San Juan Evangelista, Sayula, Soconusco, Soteapan, Texixtepec y Zaragoza (Münch, 1983: 15). En 1997, varias congregaciones de los municipios de Hidalgotitlán, Las Choapas, Minatitlán y Jesús Carranza conformaron un nuevo municipio: Uxpanapa (Guzmán, 2000).

5 Sobre la colonización agraria, tanto privada como ejidal, que los gobiernos federal y estatal promovieron en las décadas de 1940 y 1970 puede consultarse el trabajo de Revel-Mouroz (1980). La última gran oleada de colonización impulsada por el gobierno federal ocurrió entre las décadas de 1970 y 1980, años en que se pobló masivamente el valle de Uxpanapa con campesinos oriundos principalmente de La Chinantla, Oaxaca.

${ }^{6}$ Respecto a la colonización privada, consultar el estudio de Léonard (2009); información sobre la colonización dirigida por la Comisión del Papaloapan para crear Nuevos Centros de Población Ejidal puede encontrarse en los trabajos de Ewell y Poleman (1980), y Velasco y Vargas (1994). 
${ }^{7}$ Los impactos demográficos de estos sucesos han sido analizados por Palma, Quesnel y Delaunay (2000).

8 Estos datos demográficos provienen de los censos generales de población (1950, 1960 y 1970) del estado de Veracruz y fueron analizados por Nolasco (1979) y su equipo de trabajo. Esta autora advierte que en 1950 y 1960 Las Choapas eran parte del municipio de Minatitlán pero que para 1970 se había conformado como uno más de los municipios de la entidad veracruzana, de tal modo que para facilitar el análisis demográfico se recurrió a proyecciones mediante las cuales se reconstruyó la población de Las Choapas para 1950 y 1960, descartando esta población de los datos para Minatitlán.

${ }^{9}$ Entrevista con Anastasio Ramírez, 60 años, avecindado del ejido Soteapan, 5 de marzo de 2000.

${ }^{10}$ Entrevista con Anastasio Ramírez, 60 años, avecindado del ejido Soteapan, 5 de marzo de 2000.

${ }^{11}$ Entrevista con Anastasio Ramírez, 60 años, avecindado del ejido Soteapan, 5 de marzo de 2000.

${ }^{12}$ Entrevista con José Bautista, ejidatario, Tatahuicapan, 3 de mayo de 1991.

${ }^{13}$ Entrevista con Anastasio Ramírez, 60 años, avecindado del ejido Soteapan, 5 de marzo de 2000.

${ }^{14}$ Zapotitlán y Zapoapan son ejidos ubicados al oriente de la Sierra y, junto con Magallanes, Arrecifes, Piedra Labrada, Tecuanapa y La Perla del Golfo, conforman la zona ganadera de la sierra.

15 Entrevista con Juan Matías, Magallanes, municipio de Soteapan, 14 de septiembre de 1990. Actualmente, el poblado Magallanes pertenece al municipio de Tatahuicapan, el cual fue creado en 1997.

${ }^{16}$ Entrevista con Sirenio Bautista, Tatahuicapan, 30 de septiembre de 1991.

${ }^{17}$ Entrevista con Miguel Cruz, San Pedro Soteapan, 2 de noviembre de 1999.

${ }^{18}$ La Jornada, 2 de agosto de 1993.

${ }^{19}$ El Financiero, 24 de enero de 1996.

${ }^{20}$ El Financiero, 13 de enero de 1997.

${ }^{21}$ Diario de Xalapa, 19 de mayo de 1998.

${ }^{22}$ Con la desaparición de cuotas de comercialización en el caso del café- y la política "de adelgazamiento" del Estado, las entidades y organismos paraestatales se redujeron de 103 a 26 entre 1989 y 1992 (Téllez, 1994: 212).

${ }^{23}$ Cuaderno de campo, 31 de octubre de 1999.

${ }^{24}$ Entrevista con J.A.R.C., Mecayapan, 27 de julio de 2011.

${ }^{25}$ Entrevista con J.M.H., 27 años, preparatoria terminada, Mecayapan, 27 de julio de 2011.

${ }^{26}$ Entrevista con G.G., exmigrante, 29 años, Mecayapan, 27 de julio de 2011.

${ }^{27}$ Vallentin (2007: 172-74) afirma que Oteapan fue una de las primeras poblaciones del Istmo veracruzano en emprender la migración a Ciudad Juárez, la cual dio inicio a principios de 1995. La misma autora señala que estas primeras experiencias migratorias fueron difíciles pero exitosas, y a partir de ellas se difundió en el pueblo la noticia de que en Ciudad Juárez había mucho trabajo y buenos ingresos, lo cual era confirmado por el envío de remesas.

${ }^{28}$ En la Sierra de Santa Marta se tuvo acceso a la educación secundaria técnica hacia mediados de la década de 1970, cuando en cada una de las tres cabeceras municipales existentes entonces (Mecayapan, Soteapan y Pajapan) se inauguró una Secundaria Técnica Agropecuaria; en 1984 se estableció un plantel para la enseñanza del bachillerato en el poblado Tatahuicapan. Sin embargo, el acceso real a estos niveles educativos fue escaso para la mayoría de los jóvenes que vivían fuera de las cabeceras, ya que la mayor parte de las familias campesinas de las localidades no podían prescindir del trabajo de sus hijos de forma permanente y además pagarles su estancia - comida y hospedaje- en otro poblado para que ahí estudiaran. Fue hasta la década de 1990, con la apertura de telesecundarias y telebachilleratos, además de la creación en 1996 de un plantel del Colegio de Bachilleres de Veracruz (COBAEV) en Soteapan, cuando la educación secundaria y preparatoria estuvo al alcance de un mayor número de jóvenes nahuas y popolucas. Por lo que respecta a la oferta de educación universitaria, ésta se concentra principalmente en la ciudad de Coatzacoalcos, donde la Universidad Veracruzana tiene uno de sus campus $\mathrm{y}$ varias universidades privadas ofrecen licenciaturas. Desde 2006, otra opción educativa es la Universidad 
Veracruzana Intercultural (UVI), sede Selvas, ubicada en Huazuntlán, municipio de Mecayapan.

${ }^{29}$ Entrevista con G.G., exmigrante, 29 años, telebachillerato terminado, Mecayapan, 28 de julio de 2011.

${ }^{30}$ María Luisa, por ejemplo, cuenta que cuando vivió en Ciudad Juárez, entre 2002 y 2005, se escuchaba mucho sobre la violencia hacia las mujeres, así que en las maquiladoras había cartelones con recomendaciones acerca de cómo vestirse y cómo actuar para no ser agredidas; también les daban consejos sobre cómo defenderse en caso de ser atacadas. Sin embargo, pese a que ella salía de trabajar a las 12 de la noche y tenía que regresar sola en una camioneta de pasajeros, nunca tuvo algún percance. Ella rememoraba que "lo único que había entonces eran los 'cholitos' que se te acercaban y te pedían dinero para cigarros pero si les dabas unas monedas ya no te molestaban. Fue con este presidente [de la república] que la situación [de violencia] se hizo muy difícil." Entrevista con M.L.G.H., Mecayapan, 25 años, secundaria terminada, 1 de agosto de 2010.

${ }^{31}$ José Antonio, quien vivió en Ciudad Juárez en los años de apogeo de la violencia contra las mujeres (1998-2001), señala que en esos años nadie de Mecayapan murió allá pues iban de su casa al trabajo y viceversa. Él entraba a trabajar a las 7 a.m. y salía a las 4 p.m., después volvía a su casa y ya no salía. Cuando debía ir de compras con su esposa, hacían esta actividad durante la tarde, nunca de noche. Entrevista con J.A.R.C., Mecayapan, 27 de julio de 2011.

${ }^{32} \mathrm{Al}$ crédito bancario para la agricultura tenían acceso también los pequeños agricultores y ejidatarios, según informaba el gobernador del estado en 1935. En este mismo año, "el 78\% de la cartera crediticia del Banco de Sinaloa estaba invertida en el sector agrícola y el 22\% restante en la industria y el comercio" (Aguilar, 2001: 166).

33 La participación del capital norteamericano en la horticultura de Sinaloa no es reciente. Entre 1921 y 1929 dos compañías estadounidenses manejaron el 60\% de las exportaciones; en 1960 el capital norteamericano apoyaba al 80\% de los horticultores sinaloenses; y en 1995 las dificultades para acceder a créditos a largo plazo, a causa de la grave crisis financiera que enfrentó México asociada al llamado "error de diciembre" de 1994, hizo que los productores sinaloenses dependieran más del crédito externo (Gámez, 2006: 1977-79).

34 Entrevista con E.H.G., 48 años, excontratista, Mecayapan, 24 de junio de 2010.

${ }^{35}$ Entrevista con E.B., 26 años, contratista, 27 de julio de 2010.

${ }^{36}$ En 2010, la Secretaría del Trabajo, a través del Sistema Nacional de Empleo, otorgaba 1200 pesos a cada migrante para que pagara la comida y agua que consume durante el trayecto, ya que la empresa sólo les paga dos comidas durante el viaje. Se supone que este dinero debe alcanzarles también para comprar algunos víveres para sobrellevar la primera semana de trabajo, antes de que reciban su primer salario.

${ }^{37}$ No ha sido inusual que algunos jornaleros se apunten con cualquier contratista, cobren el dinero que proporciona la Secretaría del Trabajo y no se presenten el día que deben partir para Sinaloa. También se dieron casos de contratistas que entregaban a la Secretaría listas infladas de jornaleros. Por tal motivo, la Secretaría ha implementado nuevos controles para asegurar que los contratistas no cometan irregularidades, y lo mismo hacen éstos con respecto a los jornaleros.

38 Entrevistas realizadas en Mecayapan con los contratistas J.O., 44 años, 27 de junio de 2010 y B.B.C., 55 años, 30 de junio de 2010.

39 Entrevista con E.H.G., 48 años, excontratista, Mecayapan, 24 de junio de 2010.

40 Entrevista con B.B.C., contratista de jornaleros agrícolas, 55 años, Mecayapan, 30 de julio de 2010.

41 Entrevista con G.H.G., 56 años, excontratista, Mecayapan, 30 de julio de 2010.

${ }^{42}$ Entrevista con B.B.C., contratista, 55 años, Mecayapan, 30 de julio de 2010.

${ }^{43}$ Entrevista con E.B., 26 años, contratista, Mecayapan, 27 de junio de 2010.

${ }^{44}$ Entrevista con E.B., contratista, Mecayapan, 27 de junio de 2010.

${ }^{45}$ Entrevista con E.H.G., 36 años, 26 de junio de 2010.

${ }^{46}$ Entrevista con E.B., 26 años, contratista, Mecayapan, 27 de junio de 2010. 
${ }^{47}$ Entrevista con R.H.R., 38 años, contratista, Mecayapan, 26 de junio de 2010.

${ }^{48}$ Alrespecto, verlos trabajosquedan cuentadel desarrollo de la industria de tecnologías de la información y la comunicación en el área metropolitana de Guadalajara, Jalisco (Sandoval, 2012; Munguía y Correa, 2004).

${ }^{49}$ Los vidrios rotos y la maquinaria enmohecida de tres edificios contiguos ubicados en la calle Juan de la Luz Enríquez, en la ciudad de Acayucan, parecen ser el símbolo del estado actual de la actividad agropecuaria en el Istmo veracruzano. Estos edificios abandonados corresponden a las antiguas instalaciones de Liconsa, Agromaquinaria de Acayucan, y Nutrientes, Alimentos y Servicios La Palma S. de R.L. de C.V.

\section{Bibliografía}

Aguilar Aguilar, Gustavo (2001), Banca y desarrollo regional en Sinaloa, 1910-1994, México: Universidad Autónoma de Sinaloa/Plaza y Valdés.

Alemán Chang, Omar (1998), “Aumentará el desempleo en el sur. Prevés recorte de personal en complejos petroquímicos", en Diario de Xalapa, 19 de mayo, pp. 1,8 .

Anguiano Téllez, María Eugenia (1998), "Migración a la Frontera Norte de México y su relación con el mercado de trabajo regional", en Papeles de Población, núm. 17, Toluca, México: UAEM, pp. 63-79.

Anguiano Téllez, María Eugenia (2005), "Rumbo al norte: nuevos destinos de la emigración veracruzana", en Migraciones Internacionales, vol. 3, núm. 1, pp. 82-110.

Barajas, María del Rosío (2009), "Los cambios en el proceso de relocalización industrial de la Industria Maquiladora de Exportación en el norte de México", en María del Rosío Barajas, et al. (coords.), Cuatro décadas del modelo maquilador en el norte de México, México: El Colegio de la Frontera Norte, pp. 47-80.

Chiñas, Sayda (2011), "Viajarán paisanos a trabajar al norte del país, dice el SNE", en La Jornada Veracruz, 8 de agosto, p. 2.

Contreras González, Oved (1997), "Despedidos en los últimos 8 años 120 mil petroleros", en El Financiero, 13 de enero, p. 7, sección Golfo Centro.
Del Rey, Alberto y André Quesnel (2006), “Migración interna y migración internacional en las estrategias familiares de reproducción. El caso de las poblaciones rurales del sur del estado de Veracruz, México", en A. Canales (ed.), Panorama actual de las migraciones en América Latina, México: Universidad de Guadalajara/Asociación Latinoamericana de Población, pp. 427-453.

Ewell, Peter T. y Thomas T. Poleman (1980), Uxpanapa: reacomodo y desarrollo agrícola en el Trópico Mexicano, Xalapa, Veracruz: INIREB.

Gámez Gastélum, Rosalinda (2006), Hacia una cultura organizacional híbrida en empresas hortícolas, Culiacán, Sinaloa: Universidad Autónoma de Sinaloa.

Grijalva, Gabriela y Mercedes Zúñiga (2009), "Restructuración ocupacional y composición por sexo del empleo en la Industria Maquiladora de Exportación, 1990-2005", en María del Rosío Barajas et al. (coords.), Cuatro décadas del modelo maquilador en el norte de México, México: El Colegio de la Frontera Norte, pp. 219-246.

Guzmán Chávez, Mauricio G. (2000), “El municipio libre de Uxpanapa: conflicto político y conformación regional", en Sotavento. Revista de Historia, Sociedad y Cultura, núm. 7, pp. 4l-64.

Hernández Pulgarín, Gregorio (2007), “Órdenes significativos del mundo y procesos migratorios en contextos de globalización", en Beatriz Nates y Manuel Uribe (coords.), Nuevas migraciones y movilidades...Nuevosterritorios, Colombia: IRD/CIESAS/ ICANH, pp. 69-80.

Hewitt de Alcántara, Cynthia (1978), La modernización de la agricultura mexicana, 1940-1970, México: Siglo XXI.

Hualde Alfaro, Alfredo (2008), "El papel del aprendizaje y sus limitaciones en las maquiladoras mexicanas y centroamericanas", en Alicia Puyana (coord.), La maquila en México. Los desafíos de la globalización, México: FLACSO, pp. 33-58.

Lara Flores, Sara María (1998), Nuevas experiencias productivas y nuevas formas de organización flexible del trabajo en la agricultura mexicana, México: Juan Pablos/ Procuraduría Agraria. 
Lastra, Jesús (1994), "Desmantelará Pemex dos plantas en el complejo Cosoleacaque”, en La Jornada, 18 de junio.

León, Raymundo (2010), "Regresan juarochos, hartos de ver muertos”, en Diario de Xalapa, 25 de marzo, p. 10A.

Léonard, Eric (2009), "Los empresarios de la frontera agraria y la construcción de los territorios de la ganadería: la colonización y la ganaderización del Istmo central, 1950-1985”, en E. Velázquez, E. Léonard, O. Hoffmann y M. F. Prévôt-Schapira (coords.), El Istmo mexicano: una región inasequible. Estado, poderes locales y dinámicas espaciales (siglos XVI-XXI), México: CIESAS/IRD, pp. 501-573.

López, María de Jesús y Gustavo Aguilar (2004), "La actividad empresarial en el Valle de Culiacán y la agricultura, 1948-1970", ponencia presentada en el II Congreso de la Asociación Mexicana de Historia Económica, UNAM.

Münch, Guido (1983), Etnología del Istmo veracruzano, México: UNAM.

Munguía Salazar, Alex y María Antonia Correa Serrano (2004), “Especialización industrial y tecnología de la información en la zona metropolitana de Guadalajara, del estado mexicano de Jalisco, en Aldea Mundo, año 9, núm. 17, Venezuela: Universidad de Los Andes, pp. 41-54.

Nolasco, Margarita (1979), Ciudades perdidas de Coatzacoalcos, Minatitlány Cosoleacaque, México: Centro de Ecodesarrollo.

Olguín, Claudia y Georgina Tristán (1995), “Crece la tensión en el sureste de México. Dejará 71 mil desempleados el proceso de privatización", en El Financiero, 26 de agosto, p. 6.

Palma, Rafael, André Quesnel y Daniel Delaunay (2000), "Una nueva dinámica del poblamiento rural en México: el caso del sur de Veracruz (1970-1995). Apuntes sustantivos y metodológicos", en É. Léonard y E. Velázquez (coords.), El Sotavento veracruzano. Procesos sociales y dinámicas territoriales, México: CIESAS/IRD, pp. 83-108.

Prévôt-Schapira, Marie France (1994), "El sur de Veracruz en el siglo XIX: una modernización 'a marcha forzada", en O. Hoffmann y E. Velázquez (coords.), Las llanuras costeras de Veracruz. La lenta construcción de regiones, Xalapa, Veracruz: Universidad Veracruzana/Orstom, pp. 245-277.

Rabel, Cecilia, Sandra Murillo y Melba Casellas (2007), Laemigración interna indígena: Oaxaca, Guerrero y Veracruz, México: UNAM-IIS.

Revel-Muroz, Jean (1980), Aprovechamiento y colonización del trópico húmedo mexicano, México: FCE.

Rodríguez, Magdalena, "Certifica Salud campos agrícolas" (2011), en Noroeste.com, El Portal de Sinaloa, 18 de junio, 〈http://www.noroeste.com.mx/> [12 de noviembre de 2012].

Romero Miranda, Miguel Ángel (1998), "Sur de Veracruz", en La Jornada, 30 de abril.

Sánchez Hernández, Marissa (1996), "Notorio incremento de desempleo en la zona sur", en El Financiero, 24 de enero, p. III, sección Golfo Centro.

Sánchez-Salazar, María Teresa, et al. (1999), "Industria petroquímica y cambios socioeconómicos en la costa del Golfo de México. El caso del sureste de Veracruz", en Investigaciones Geográficas, núm. 40, pp. 127-147.

Sandoval García, Edgar Roberto (2012), "El Valle del Silicio mexicano ¿Un caso de ventaja competitiva en el país?, en Revista Universitaria Digital de Ciencias Sociales, 24 de febrero, vol. 3, núm. 4, pp. 1-10.

Téllez, Luis (994), La modernización del sector agropecuario y forestal, México: FCE.

Texis, Michelle, Alejandro Mungaray y Gabriela Grijalva (2009), "Maquiladoras y organización industrial en la frontera norte", en María del Rosío Barajas et al. (coords.), Cuatro décadas del modelo maquilador en el norte de México, México: El Colegio de la Frontera Norte, pp. 29-45.

Uribe, Manuel (2009), "La población zapoteca en el Istmo veracruzano: redes sociales y territorialidad", en É. Velázquez, E. Léonard, O. Hoffmann y M.F. Prévôt-Schapira (coords.), El Istmo mexicano: una región inasequible. Estado, poderes locales y dinámicas espaciales (siglos XVI-XXI), México: CIESAS/IRD, pp. 635-676.

Vallentin Jorth Boisen, Sussan (2007), Migración, globalización y flujos transregionales. Etnografía del 
procesos migratorio del sur de Veracruz a la frontera norte, (tesis inédita de doctorado). Instituto de Investigaciones Antropológicas de la UNAM, México.

Velasco Toro, José y Guadalupe Vargas Montero (1994), "Uxpanapa, construcción y fracaso de una región plan”, en O. Hoffmann y E. Velázquez (coords.), Las llanuras costeras de Veracruz. La lenta construcción de regiones, Xalapa, Veracruz: Universidad Veracruzana/ Orstom, pp. 279-308.

Velázquez, Emilia (2000), “Ganadería y poder político en la Sierra de Santa Marta”, en É. Léonard y E. Velázquez (coords.), El Sotavento veracruzano. Procesos sociales y dinámicas territoriales, México: CIESAS/IRD, pp. 111-127.

Velázquez, Emilia (2006), Territorios fragmentados. Estado y comunidad indígena en el Istmo veracruzano, México: CIESAS/El Colegio de Michoacán.

Velázquez, Emilia (2010), "La población indígena del sur de Veracruz: entre la permanencia y la movilidad", en E. Florescano y J. Ortiz Escamilla (coords.), Atlas del patrimonio natural, histórico y cultural de Veracruz, t. III, Patrimonio Cultural, coordinado por Córdova Plaza, Rosío, Veracruz: Gobierno del Estado/Universidad Veracruzana, pp. 89-104.

Zamudio, Isabel (2010), "Retorna a Veracruz grupo de juarochos”, en Milenio Diario, 3 de mayo. 